\title{
Molecular Characterization of Maize Inbred Lines against Stalk Rot Complex of Maize (Zea mays L.)
}

\author{
Gopala $^{1}$, Robin Gogoi ${ }^{1 *}$, Firoz Hossain ${ }^{2}$, K.S. Hooda ${ }^{3}$ and J.C. Sekhar \\ ${ }^{1}$ Division of Plant Pathology, ${ }^{2}$ Division of Genetics, ICAR-Indian Agricultural Research \\ Institute, New Delhi 110 012, India \\ ${ }^{3}$ ICAR-Indian Institute of Maize Research, New Delhi 110 012, India \\ ${ }^{4}$ Winter Nursery Centre, ICAR- Indian Institute of Maize Research \\ Rajendranagar, Hyderabad-500 030, India \\ *Corresponding author
}

\begin{tabular}{|c|c|}
\hline & A B S T R A C T \\
\hline Keywords & \multirow{7}{*}{$\begin{array}{l}\text { Stalk rot complex of maize (Zea Mays L.) caused by Macrophomina phaseolina } \\
\text { (Tassi) Goid and Fusarium verticilloides (Sacc) Nirenberg reduces yield directly } \\
\text { by affecting the physiological activity of the plants and finally cause lodging, } \\
\text { which is the main reason of economic losses. Screening of Indian maize inbreds } \\
\text { for the resistance to pathogen was done using } 34 \text { Simple Sequence Repeats (SSR) } \\
\text { markers available in database. Among these SSR markers, two markers viz. SSRZ } \\
135 \text {, and SSRZ } 319 \text { showed polymorphism for resistance to stalk rot. The marker } \\
\text { SSRZ } 319 \text { located on chromosome } 1 \text { distinguished the resistant lines H } 109 \text {, P } \\
503 \text {, P } 408 \text { and E } 618 \text { from the susceptible lines viz., H- } 8 \text {, P } 320 \text {, P } 373 \text { and } 18834 \text {. } \\
\text { Resistant genotypes identified in the study would serve as potential donors in the } \\
\text { stalk rot resistance breeding programme. Further, QTL qRfg } 2 \text { with most likely } \\
\text { presence in the Indian maize inbred lines can be transferred to elite inbreds using } \\
\text { marker-assisted selection. }\end{array}$} \\
\hline Quantitative trait & \\
\hline loci (QTL), Simple & \\
\hline $\begin{array}{l}\text { Sequence Repeats } \\
\text { (SSR) Markers }\end{array}$ & \\
\hline $\begin{array}{l}\text { Screening, Maize } \\
\text { genotypes. }\end{array}$ & \\
\hline Article Info & \\
\hline $\begin{array}{l}\text { Accepted: } \\
\text { 04 June } 2017 \\
\text { Available Online: } \\
\text { 10 July } 2017\end{array}$ & \\
\hline
\end{tabular}

\section{Introduction}

Stalk rot is a major disease of maize causing appreciable damage to the standing crop and may infect all types of corn (Renfro and Ullastrup, 1976). According to Sharma et al., (1993), maize production in India is severely limited due to the incidence of a soil borne disease commonly called Post- flowering stalk rot (PFSR).

Apart from grain yield, PFSR reduces the fodder quality. The disease is caused by pathogen complex comprising three fungi, viz., Cephalosporium acremonium,
Macrophomina phaseolina, Fusarium moniliformae and one bacterial Erwinia carotovora var. zeae (Shankar, 2003). In India, the disease is prevalent in most of the maize growing areas viz., Jammu and Kashmir, Punjab, Haryana, Delhi, Rajasthan, Madhya Pradesh, Uttar Pradesh, Bihar, West Bengal, Andhra Pradesh, Tamil Nadu and Karnataka, where water stress occurs after flowering stage of the crop (Singh et al., 2012). PFSR is basically a soil borne disease for which fungicidal control of stalk rot is not much effective. Hence, discovery and 
utilization of resistance genes to improve maize tolerance to stalk rot is a cost effective and environment friendly approach to reduce the grain yield loss (White, 1999). Through the extensive research done at Directorate of Maize Research, sources of resistance against the PFSR of maize have been identified (Kumar and Shekhar, 2005; Sekhar et al., 2010; Hooda et al., 2012). Parallelly, a large number of efforts are being diverted towards development of biotechnological tools for identification and tagging of genes conferring resistance to PFSR. For Fusarium stalk rot resistance a major gene (Yang et al., 2004) and five QTL (Pe et al., 1993) have been reported on the different chromosomes. Yang et al., (2010) detected two loci QTL qrfgl and $q r f g$ 2, conferring resistance to Fusarium stalk rot. There are four genomic regions exist in the maize genome involved in the determination of resistance to $M$. phaseolina. In contrast to this progress, study on the genetics of resistance to charcoal rot or PFSR complex under Indian scenario is lagging behind and also information like molecular markers linked to stalk rot resistance, genetic diversity in maize inbreds related to PFSR complex have not been generated. Owing to this reason, present study was conducted for molecular characterization of some important Indian maize inbred lines with respect to the PFSR complex resistance.

\section{Materials and Methods}

\section{Screening of maize genotypes in field}

\section{Preparation of inoculum}

Isolation of $F$. verticilloides from the infected maize plants and preparation of inoculum from its pure cultures in PDA.

\section{Raising and screening of genotypes}

Twenty four maize genotypes collected from Winter Nursery Centre (WNC), Hyderabad were raised in field during kharif, 2013 following all agronomic practices during the cropping season. Plants of 45-50 days old were inoculated by the toothpick method (Payak, 1985) just after flowering. Disease scoring was done at the time of harvesting in field on a 1-9 scale (Payak and Sharma, 1983).

\section{Molecular characterization of the genotypes with specific markers}

\section{Leaf sampling}

Leaf samples were collected from 30-days old field grown plants (3-4 leaf stage), wrapped in marked aluminium foil and then frozen in $\mathrm{LN}_{2}$ before storing in $-80^{\circ} \mathrm{C}$.

DNA isolation, purification and quantification

DNA isolation from the leaf samples was carried out using the modified CTAB method (Saghai-Maroof et al., 1984) optimized at Maize Genetics Unit, Division of Genetics, IARI. The DNA was dissolved in Tris-EDTA buffer (1 M Tris: 0.5 M EDTA) and quantified using a Spectrophotomer (Bio-Tek Instruments, USA). The quality of DNA was checked using $0.8 \%$ agarose gel electrophoresis, followed by dilution with TrisEDTA buffer to the concentration $10 \mathrm{ng} / \mu \mathrm{l}$, the final concentration for PCR reaction. DNA quantification was also done directly by loading $1 \mu \mathrm{l}$ of DNA in Nanodrop spectrophotometer (Thermo Scientific Model).

\section{PCR amplification}

A set of 30 SSR (Simple Sequence Repeat) markers (Table 1, Sl. No. 1-30) were selected carefully from all 10 chromosomes depicted in public domain MaizeGDB; http://www.maizegdb.org. Another four SSR (S1. No. 31-34) and two CAPS (Sl. No. 35-36) markers were taken from $\mathrm{R}$ gene specific marker reported by Zhang et al., (2012). Using 
all the 34 markers, PCR amplifications were performed in a BIORAD Thermal Cycler with a final reaction volume of $10 \mu \mathrm{l}$ having $\sim 30-40$ ng of genomic DNA.

The protocol for the PCR amplification consisted of an initial denaturation at $94^{\circ} \mathrm{C}$ for 4 min, followed by about 35 cycles of $94^{\circ} \mathrm{C}$ for $30 \mathrm{sec}$ (denaturation), $\mathrm{X}^{\circ} \mathrm{C}$ for $30 \mathrm{sec}$ (annealing), and $72^{\circ} \mathrm{C}$ for $45 \mathrm{sec}$ followed by extension at $72^{\circ} \mathrm{C}$ for $7 \mathrm{~min}$. The $\mathrm{X}^{\circ} \mathrm{C}$ refers to the annealing temperature which varied (ranging from $52-62^{\circ} \mathrm{C}$ ) with each primer.

\section{Resolution of PCR amplified products and scoring of marker profiles}

The PCR amplified product for each SSR marker was resolved through gel electrophoresis in a horizontal gel system using 1.0X TBE buffer (Sambrook et al., 1989). Ethidium bromide $(10 \mathrm{mg} / \mathrm{ml})$ was used for staining, 4\% Biorose agarose gel was used. At both ends of the gel, $50 \mathrm{bp}$ DNA ladder (MBIFermentas) was loaded and images were recorded using a Gel Documentation System (Alpha Innotech, USA), followed by scoring of marker profiles.

\section{Results and Discussion}

\section{Phenotyping of maize inbred lines for} resistance to stalk rot

In order to characterize the maize inbred lines for resistance to Fusarium stalk rot, a set of 24 maize inbred lines viz., $\mathrm{H}-8, \mathrm{H}-62, \mathrm{H}-61$, BML-6, H-139, 14933, H109, H10, P503, H75, P320, H182, H103, P408, H37, P364, H68, 14982, E613, P373, E618, 18527, 18768 and 18834 were used in the current study. The inbred lines were evaluated under artificial epiphytotic condition created by toothpick method of inoculation. Among the inbred lines studied, four inbred lines H 109, P 503, P 408 and $\mathrm{E} 618$ were found to be resistant and $\mathrm{H}-8$, $\mathrm{P}$ 320, P 373 and 18834 were found to be highly susceptible (Table 2). Majority of the lines namely H-62, BML-6, H-139, 14933-2, 14933-1, H 75, H 37, H 68, 14982-5, 18527 and 18768 were found to be moderately resistant and seven lines namely H-61, H10, DMSC-I, H 182, H 103, P 364 and E 613 were moderately susceptible.

\section{Molecular characterization of maize inbred lines for stalk rot resistance}

Out of the 34 SSR markers used for characterization of maize genotypes, 32 yielded monomorphic band across 24 genotypes. CAPS markers viz., CAPSZ406 and CAPSZ459 also showed monomorphic band in all the genotypes. Two SSR markers flanking the QTL $q R f g 2$ viz., SSRZ135 and SSRZ319 located at physical position of $227.4 \mathrm{Mb}$ and $261.65 \mathrm{Mb}$, respectively on chromosome 1 showed polymorphism among the 24 germplasm used in the current study. The marker SSRZ135 showed two allele of 180bp and 200bp size (Fig. 1), whereas 160bp and $150 \mathrm{bp}$ alleles could be resolved by using the marker SSRZ319. The marker SSRZ319 distinguished all the four stalk rot resistant genotypes viz., H 109, P 503, P 408 and E 618 each of them possessing 150bp allele (Fig. 2), while susceptible genotypes viz., H-8, P 320, P 373 and 18834 possessed 160bp allele (Table 3). Although the other marker SSRZ135 revealed polymorphic bands, but it failed to distinguish between the resistant and susceptible inbred lines. Fusarium stalk rot is one of the devastating diseases of Maize in India. Therefore, understanding the genetics of the resistance is of utmost importance in order to develop high yielding disease resistance maize varieties. Of the several Fusarium stalk rot resistant QTLs identified, the QTL $q R f g 2$ located on chromosome 1 explaining the phenotypic variance of $\sim 8.9 \%$ has been identified in resistant maize inbred line ' 1145 ' (Zhang et al., 2012). The QTL $q R f g 2$ is flanked by the markers SSRZ319 and SSRZ135. 
Table.1 List of primers used for molecular characterization maize inbred lines

\begin{tabular}{|c|c|c|c|c|}
\hline S. No. & Markers & FORWARD PRIMER & REVERSE PRIMER & Location \\
\hline 1 & umc1335 & ATGGCATGCATGTGTTTGTTTTAC & ACAGACGTCGCTAATTCCTGAAAG & 1.06 \\
\hline 2 & umc1280 & AAAATCCATGGCTTCTTTCTTTCC & AACAGCCAGTTTTGGGCTGTATAA & 10.05 \\
\hline 3 & umc1590 & CAGAGTCTGATAGTCCGAACCCAG & GTAAAGCTCACAGCTTCCGACAG & 1.04 \\
\hline 4 & umc1035 & CTGGCATGATCACGCTATGTATG & TAACATCAGCAGGTTTGCTCATTC & 1.06 \\
\hline 5 & umc1245 & TGGTTATGTGCATGATTTTTCCTG & CATGCGTCTGATCTTCAGAATGTT & 1.07 \\
\hline 6 & $\mathrm{mmc0041}$ & AGGACTTAGAGAGGAAACGAA & $\begin{array}{l}\text { TTTATCCTTACTTGCAGTTGC } \\
\end{array}$ & 1.08 \\
\hline 7 & umc1396 & TTCGATTATTCCATTGAGCCTCTG & CTCCTAACGCAGGAGACAAGAGAG & 1.06 \\
\hline 8 & umc 1358 & AGAACCTCCCGCTTGACGAC & ACCTCAACCTCGACCTCTGCAT & 1.07 \\
\hline 9 & umc1570 & CAGGAGATGATGAGCGGGAG & GTCGTAGAGGTGGTGCTGCTG & 9.04 \\
\hline 10 & umc1571 & GCACTTCATAACCTCTCTGCAGGT & CACCGAGGAGCACGACAGTATTAT & 9.04 \\
\hline 11 & STS & CGCAATTCACCACATCATTTTA & CAACTACGTCGGATAGAACAA & - \\
\hline 12 & HM1 & CGGATTCGTCTGCTGGTGGGTGTGC & GATGTCGAGGTGAGGGAAC & - \\
\hline 13 & umc1920 & GGTTCGGGTTTGCTACGTGTT & ACGAGACAACACAACCAAGACAAA & 3.04 \\
\hline 14 & umc2000 & CTGTTGTCAAGCCAAGCCAGT & $\begin{array}{l}\text { AGGCTTGTGAGACTCAGCAGTTTT } \\
\end{array}$ & \\
\hline 15 & umc1634 & TCCGTTGAGGACACTCGAATTTAT & GTAGCCTGCAAAACATCCAAGAAC & 9.03 \\
\hline 16 & umc1505 & TTACACAGAAGCCCATTTGAAGGT & GGATGGTTGTTGGTGGTGTAGAAT & 9.08 \\
\hline 17 & umc 1813 & CTGTACATGGATATGGCATTGGTG & GCATATACACCACCTTGGACAACA & 3.09 \\
\hline 18 & umc1926 & ATGCCAGCATTCTTCATCCTACAT & TGAGGCTTGGTCCACTAAAGAAAG & 4.03 \\
\hline 19 & umc1142 & CCGAAAACCCATTCTTCTAGCATC & GTGCGGTGTTCTCTCTTTCACTCT & 4.05 \\
\hline 20 & umc1656 & AGTTTTGACCGCGCAAAAGTTA & GTACGAGCAGGCCATTAACCC & 6.02 \\
\hline 21 & y1 & CAAGAAGAGGAGAGGCCGGA & TTGAGCAGGGTGGAGCACTG & 6.01 \\
\hline 22 & umc56 & CAACTCATCTTTGATAGGGCAACC & ACCCAGCTCCATTAATAACCCAAT & 7.03 \\
\hline 23 & phi091 & ATCTTGCTTCCATAAGATGCACTGCTCT & CTCAGCTTCGGTTCCTACACAGT & 7.03 \\
\hline 24 & umc1245 & TGGTTATGTGCATGATTTTTCCTG & CATGCGTCTGATCTTCAGAATGTT & 1.07 \\
\hline 25 & bmc1556 & ACCGACCTAAGCTATGGGCT & CCGGTTATAAACACAGCCGT & 1.07 \\
\hline 26 & umc1947 & GGATCTCACCCCCTGCTGTC & ATCACGCGCTCACTCTCCTCT & 2.08 \\
\hline 27 & umc1943 & GTGCTGCAGAATTCAACTCCTTC & ACCATTTCTGCGTTTCCACAGT & 4.02 \\
\hline 28 & bnlg1931 & GGGATGCTCGTAGTAGGGGT & ACGCACACAACAAAGAGACG & 3.07 \\
\hline 29 & bnlg2244 & CAGGAAAACGAAAACCCAGA & CTACGCGGGTCTCATCTCAT & 4.08 \\
\hline 30 & bnlg1456 & CTCTAGGTGGTTAAGATTAACTCATT & TTCATGAGGACCGTGTTGAA & 3.05 \\
\hline 31 & SSRZ135 & CCGATCCTCCTCCTTCAG & CTGACGTAGTGCTGCGA & 1.09 \\
\hline 32 & SSR334 & TTCGAGCATGCCAAAGAA & GGTGCACACAGACATGG & - \\
\hline 33 & SSRZ319 & CACCTTCCTCTTGCTGTC & CTGCACCTGCTAGTCCTG & 1.09 \\
\hline 34 & SSR58 & GACGCTGCACAATAGGTT & TCATTATACACCGACGACC & - \\
\hline 35 & CAPSZ459 & GCAATCGGAATTTAGGG & GCATAACTCGGCTGGCAT & - \\
\hline 36 & CAPSZ406 & GATACATGCACAGAAG & GTCCATTGTCACCACTGA & - \\
\hline
\end{tabular}


Table.2 Markers, location on chromosome and their amplification

\begin{tabular}{|c|c|c|c|}
\hline S. No. & Markers & Bin Location & Allelic Polymorphic \\
\hline 1 & umc1335 & 1.06 & Monomorphic \\
\hline 2 & umc 1280 & 10.05 & Monomorphic \\
\hline 3 & umc 1590 & 1.04 & Monomorphic \\
\hline 4 & umc 1035 & 1.06 & Monomorphic \\
\hline 5 & umc1245 & 1.07 & Monomorphic \\
\hline 6 & $\mathrm{mmc0041}$ & 1.08 & Monomorphic \\
\hline 7 & umc1396 & 1.06 & Monomorphic \\
\hline 8 & umc 1358 & 1.07 & Monomorphic \\
\hline 9 & umc 1570 & 9.04 & Monomorphic \\
\hline 10 & umc1571 & 9.04 & Monomorphic \\
\hline 11 & STS & - & Monomorphic \\
\hline 12 & HM1 & - & Monomorphic \\
\hline 13 & umc1920 & 3.04 & Monomorphic \\
\hline 14 & umc 2000 & & Monomorphic \\
\hline 15 & umc1634 & 9.03 & Monomorphic \\
\hline 16 & umc 1505 & 9.08 & Monomorphic \\
\hline 17 & umc1813 & 3.09 & Monomorphic \\
\hline 18 & umc1926 & 4.03 & Monomorphic \\
\hline 19 & umc1142 & 4.05 & Monomorphic \\
\hline 20 & umc1656 & 6.02 & Monomorphic \\
\hline 21 & y1 & 6.01 & Monomorphic \\
\hline 22 & umc56 & 7.03 & Monomorphic \\
\hline 23 & phi091 & 7.03 & Monomorphic \\
\hline 24 & umc 1245 & 1.07 & Monomorphic \\
\hline 25 & bmc 1556 & 1.07 & Monomorphic \\
\hline 26 & umc1947 & 2.08 & Monomorphic \\
\hline 27 & umc1943 & 4.02 & Monomorphic \\
\hline 28 & bnlg1931 & 3.07 & Monomorphic \\
\hline 29 & bnlg2244 & 4.08 & Monomorphic \\
\hline 30 & bnlg1456 & 3.05 & Monomorphic \\
\hline 31 & SSRZ135 & 1.09 & Polymorphism \\
\hline 32 & SSR334 & - & Monomorphism \\
\hline 33 & SSR319 & 1.09 & Polymorphism \\
\hline 34 & SSR58 & - & Monomorphism \\
\hline 35 & CAPSZ459 & - & Monomorphism \\
\hline 36 & CAPSZ406 & - & Monomorphism \\
\hline
\end{tabular}


Table.3 Genotypic score of 24 maize inbred line generated using markers linked to Fusarium stalk resistance QTL $q R f g 2$

\begin{tabular}{|c|c|c|c|c|}
\hline $\begin{array}{c}\text { Lane } \\
\text { No. }\end{array}$ & Inbreds & Primer (SSRZ 135) & Primer (SSRZ319) & Reaction \\
\hline 2 & H-62 & 180 & 150 & MR \\
\hline 4 & BML-6 & 200 & NA & MR \\
\hline 5 & H-139 & 200 & 150 & MR \\
\hline 6 & 14933 & 200 & 160 & MR \\
\hline 11 & H 75 & 180 & 150 & MR \\
\hline 16 & H 37 & 200 & 160 & MR \\
\hline 18 & H 68 & 180 & 160 & MR \\
\hline 19 & $14982,-5$ & 200 & 150 & MR \\
\hline 20 & 18527 & 200 & 160 & MR \\
\hline 24 & 18768 & 200 & 150 & MR \\
\hline 3 & H-61 & NA & 160 & MS \\
\hline 8 & H 10 & 180 & 160 & MS \\
\hline 13 & H 182 & 180 & 150 & MS \\
\hline 14 & H 103 & NA & 150 & MS \\
\hline 17 & P 364 & 180 & 150 & MS \\
\hline 23 & E 613 & 200 & 150 & MS \\
\hline 7 & H 109 & 200 & 150 & R \\
\hline 9 & P 503 & 180 & 150 & R \\
\hline 15 & P 408 & 200 & 160 & R \\
\hline 22 & E 618 & 200 & 150 & R \\
\hline 1 & H-8 & 200 & 160 & S \\
\hline 12 & P 320 & 200 & 160 & S \\
\hline 21 & P 373 & 200 & 150 & S \\
\hline 10 & 18834 & 200 & 160 & S \\
\hline NA No & & & \\
\hline
\end{tabular}

NA: Not amplified

In the present study, SSRZ319 was efficient in distinguishing the resistant and susceptible maize inbred lines. This suggests that Indian maize inbred lines that plays role in governing resistance to Fusarium stalk rot in maize, is most likely to possess QTL $q R f g 2$. However, the other flanking marker SSRZ135 could not distinguish the resistant and susceptible maize inbred lines. This could be attributed to usage of different sets of genotypes (used in the present study), where distance between the QTL and markers is more (Zhang et al.,
2012). Due to this, the possibility of high occurrence of recombination between the gene and the marker would be more, thereby leading to random presence of both the alleles among resistant and susceptible inbreds.

The present study, thus characterized a set of diverse inbreds for their reaction to Fusarium stalk rot. Resistant genotypes identified in the study would serve as donors in the resistance breeding programme. QTL $q R f g 2$ with most likely presence in the resistant inbreds can be 
transferred to elite inbreds using markerassisted selection. Breeding with the assistance of molecular marker have been reported to be successful in case of developing resistance against different stresses in maize such as common smut (Ding et al., 2008), head smut (Li et al., 2008), Fusarium moniliforme ear rot (Zhang et al., 2006), banded leaf and sheath blight (BLSB) (Zhao et al., 2006), Maize Dwarf Mosaic Virus (MDMV) disease (Liu et al., 2006) and Sugarcane Mosaic Virus (SCMV) disease (Zhang et al., 2003)

\section{Acknowledgement}

Authors are thankful to the Indian Council of Agricultural Research providing fellowship for pursuing M.Sc., programme and also thankful to the winter nursery center (Indian Institute of Maize Research), Rajendranagar, Hyderbad for providing maize inbred lines.

\section{References}

Ding, J.Q., Wang, X.M., Chander, S., Li, J.S. 2008. Identification of QTL for maize resistance to common smut by using recombinant inbred lines developed from the Chinese hybrid Yuyu22. J.Appl.Genet.49:147-154.

Hooda, K. S. 2012. Identifying sources of multiple disease resistance in maize. Maize J. 1(1):82-84.

Kumar, S., Shekhar, M. 2005. Stress on Maize in Tropics Eds. Published by Directorate of Maize Research, Cummings Laboratory, Pusa Campus, New Delhi. Angkor Publisher (P) Ltd. Noida. 172- 194.

Li, X.H.,Wang, Z.H., Gao, S.H., Shi, H.L., Zhang, S.H.,George,M.L.C., Li,M.S., Xie. C.X. (2008) Analysis of QTL for resistance to head smut (Sporisorium reiliana) in maize. Field Crops Res. 106:148-155
Liu, X., He, D., Zhang, H. 2006. QTL mapping for resistance to MDMV2B in maize. J. Agric. Univ. Hebei 29:56-59.

Payak, M.M., Sharma, R.C. 1983. Influence of some environmental and host factors on Pythium stalk rot of maize. Indian Phytopath. 33: 10-15.

Payak, M.M., Sharma, R.C. 1985. Maize diseases and approaches to their management in India. Trop. Pest. Manag. 31: 302-310

Pe, M. E., Gianfranceschi, L., Taramino, G., Tarchini, R., Angelini, P., Dani, D. Binelli, G. 1993. Mapping quantitative trait loci QTLs for resistance to Gibberella zeae infection in maize. Mol. Gen. Genet. 241: 11-16.

Renfro, B. L Ullstrup, A.J. 1976. A comparison of maize diseases in temperate and tropical environments. PANS 22:491-498.

Shankar Lingam, S. 2003. Maize diseases and their management. In: Manual on "Issues in Hybrid maize Technology", ANGRAU-DMR (ICAR) publication 42: 66-73.

Sharma, R.C., Carlos, D. L., Payak, M.M. 1993. Diseases of maize in South and South East Asia: problems and progress crop protection 12: 414-422.

Singh, N., Rajendran A., Meena, S. and Mittal, G. 2012. Biochemical response and host-pathogen relation of stalk rot fungi in early stages of maize (Zea mays L.) African J. Biotech. 11(82): 1483714843.

White, D. G. 1999. Fungal stalk rots. Compendium of Corn Diseases $3^{\text {rd }}$ Edition. (Ed. D. G. White). APS Press. St. Paul, MN.

Yang, D. E., Zhang, C. L., Zhang, D.S, Jin, D.M., Weng, M. L., Chen, S.T. Nguven, H.2004. Genetic analysis and molecular mapping of maize stalk rot resistance gene Rfg1. Theor. Appl. Genet. 108:4 706-711. 
Yang, Q., Yin, G., Guo, Y., Zhang, D., Chen, S. Mingliang, Xu. M. 2010. A major QTL for resistance to Gibberella stalk rot in maize. Theor. Appl. Genet. 121: 673-87.

Zhang, F., Wan, X. Q., Pan, G. T. 2006. QTL mapping of Fusarium moniliforme ear rot resistance in maize. 1. Map construction with microsatellite and AFLP markers. J. Appl. Genet. 47: 9-15

Zhang, S. H., Li, X. H., Wang, Z. H., George,
M. L., Jeffer, D., Wang, F. G., Liu, X. D., Li, M. S. and Yuan, L. X. 2003. QTL mapping for resistance to SCMV in Chinese maize germplasm. Maydica 48:307-312.

Zhao, M. J., Zhang, Z. M, Zhang, S. H., Li, W. C., Jeffers, D. P, Rong, T. Z. and Pan, G. T. 2006. Quantitative trait loci for resistance to banded leaf and sheath blight in maize. Crop Sci. 46: 10391045.

\section{How to cite this article:}

Gopala, Robin Gogoi, Firoz Hossain and Hooda, K.S. 2017. Molecular Characterization of Maize Inbred Lines against Stalk Rot Complex of Maize (Zea mays L.). Int.J.Curr.Microbiol.App.Sci. 6(7): 230-237. doi: https://doi.org/10.20546/ijcmas.2017.607.027 